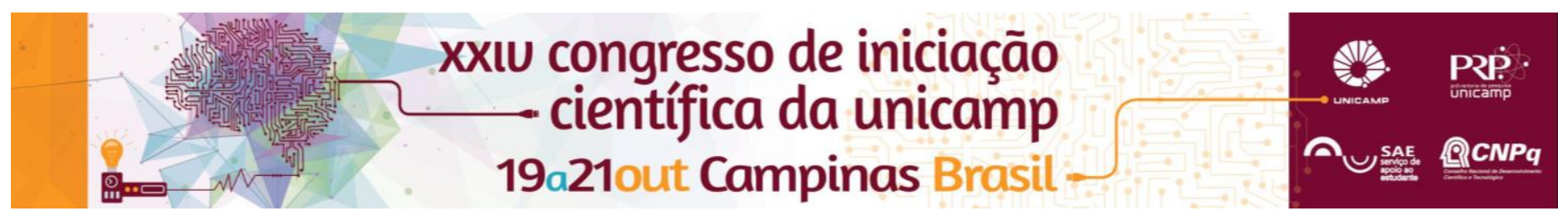

\title{
Avaliação da Qualidade de Vida dos Pacientes com Síndrome de Treacher Collins por meio do Instrumento de Qualidade de Vida da OMS (WHOQOL-100)
}

\author{
Jéssica P. Oliveira*, Fernando F. Lodovichi, Rafael Denadai, Cesar A. Raposo-Amaral, Miriam Benincasa, Eda M. \\ Custódio, Enrico Ghizoni, Cassio E. Raposo-Amaral.
}

\section{Resumo}

A Síndrome de Treacher Collins (STC) é uma desordem caracterizada por dismorfismo facial pronunciado, o que requer tratamento complexo. Doze pacientes com STC responderam ao questionário de qualidade de vida (QV) da OMS, WHOQOL-100. Os resultados foram comparados aos do grupo controle. Em 5 dos 6 domínios avaliados, o grupo com STC apresentou escore superior ao grupo controle. O domínio ambiente apresentou diferença significativa. Os indivíduos com STC não apresentam QV inferior ao grupo controle.

\section{Palavras-chave:}

Síndrome de Treacher-Collins, Qualidade de vida .

\section{Introdução}

A Síndrome de Treacher Collins (STC) é uma desordem transmitida em um padrão autossômico dominante, caracterizada por alterações morfológicas faciais pronunciadas (figura 1), compondo um grande espectro clínico, o que requer um tratamento longo e multidisciplinar. Há desta forma, a necessidade de avaliação do impacto que a abordagem da síndrome tem sobre os pacientes e verificar a influência dos resultados dos procedimentos cirúrgicos e de outros aspectos do tratamento. Realizamos a hipótese de que os pacientes com STC, acompanhados e tratados por equipe multidisciplinar, pudessem apresentar elevados índices de qualidade de vida (QV), mas que não se assemelhariam a indivíduos não afetados. Objetivos: Avaliação da QV dos pacientes com STC por meio do questionário de qualidade de vida da OMS (WHOQOL 100) e comparação com grupo controle.

\section{Resultados e Discussão}

Doze voluntários com STC em acompanhamento exclusivo na instituição (de 2005 a 2013), responderam ao questionário de qualidade de vida da OMS, WHOQOL-100. Os resultados foram comparados por meio do teste ANOVA aos do grupo controle, constituído por 2434 estudantes do Ensino Médio avaliados em 2010 no estudo "Avaliação da qualidade de vida em adolescentes do município de São Paulo" 1 . O nível de significância estatística foi estabelecido para $p<0,05$.

Resultados: em 5 dos 6 domínios avaliados pelo questionário, o grupo dos pacientes apresentou escore superior ao grupo controle, à exceção do domínio "nível de independência". O domínio ambiente mostrou-se com diferença significativa. (Tabela 1).

Discussão: Estes escores mais altos provavelmente são resultado do ambiente de cuidados multidisciplinar (com protocolo cirúrgico adequado e acompanhamento psicológico). Sendo que Ritchie et $\mathrm{al}^{2}$ já determinou que a auto avaliação em saúde para acompanhamentos superiores a 3 meses são estatisticamente significativos.

$\mathrm{Na}$ literatura, também encontramos evidências de que em vários grupos de pessoas com algum tipo de limitação, a autoestima é igual ou superior a pessoas não afetadas, como deficientes físicos ${ }^{3}$, por exemplo. Pessoas que enfrentam e superam adversidades consideram-se com QV superior a períodos anteriores em suas vidas? O WHOQOL-100 é preenchido baseando-se nas 2 semanas que antecederam seu preenchimento.

Tabela 1. Escores dos domínios do WHOQOL-100

\begin{tabular}{|c|c|c|c|}
\hline DOMÍNIOS & STC & Controle & P-VALOR \\
\hline Físico & 67,88 & 64,77 & 0,417 \\
\hline Psicológico & 73,54 & 70,27 & 0,382 \\
\hline Independência & 77,43 & 79,26 & 0,557 \\
\hline Relações & 76,71 & 70,80 & 0,122 \\
sociais & & & \\
\hline Ambiente & 68,36 & 58,17 & 0,003 \\
\hline Espiritualidade & 80,11 & 70,31 & 0,131 \\
\hline
\end{tabular}

\section{Conclusões}

O grupo de indivíduos com STC não apresenta qualidade de vida inferior ao grupo controle, contrariando nossa hipótese inicial.

\section{Agradecimentos}

Agradecemos ao PIBIC/ SAE por incentivar esta pesquisa.

Figura 1. Criança com diagnóstico de STC

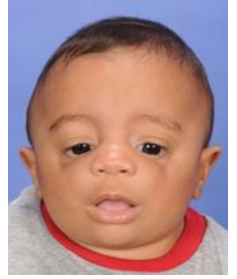

${ }^{1}$ Benincasa M, Custodio EM. Avaliação da qualidade de vida em adolescentes do Município de São Paulo. Bol. psicol [online]. 2011;61(134):31-42.

${ }^{2}$ Ritchie C, Andersen R, et al. Implementation of an Interdisciplinary, TeamBased Complex Care Support Health Care Model at an Academic Medical Center: Impact on Health Care Utilization and Quality of Life. Cameron DW, ed. PLoS ONE. 2016;11(2):e0148096. doi:10.1371/journal.pone.0148096.

${ }^{3}$ Salehi M, Kharaz Tavakol H, et al. The Relationship Between Self-Esteem and Sexual Self-Concept in People With Physical-Motor Disabilities. Iranian Red Crescent Medical Journal. 2015;17(1):e25359. doi:10.5812/ircmj.25359. XXIV Congresso de Iniciação Científica da UNICAMP 